\title{
Role of Chest X-Ray in Assessing Severity of Pneumonia in Children: A Study in Dhaka Shishu (Children) Hospital, Dhaka, Bangladesh
} Mohammad Mahbub Hossain ${ }^{1 *}$, Abu Ishaque khan ${ }^{2}$, MM Monowara ${ }^{3}$, A.K.M. Khairul Islam ${ }^{4}$

${ }^{1}$ Assistant Professor, Department of Radiology \& Imaging, Dhaka Shishu (Children) Hospital, Dhaka, Bangladesh

${ }^{2}$ Professor, Dept. of Radiology \& Imaging, Dhaka Shishu (Children) Hospital, Dhaka, Bangladesh

${ }^{3}$ Assistant Professor, Department of Radiology \& Imaging, Dhaka Shishu (Children) Hospital, Dhaka, Bangladesh

${ }^{4}$ RMO, Emergency, Observation and Referral Unit, Dhaka Shishu (children) Hospital, Dhaka, Bangladesh

DOI: $10.36347 /$ sjams.2020.v08i11.004

| Received: 19.10.2020 | Accepted: 27.10.2020 | Published: 06.11.2020

*Corresponding author: Mohammad Mahbub Hossain

Abstract

Original Research Article

Introduction: Community acquired pneumonia (CAP) is defined clinically as presence of signs and symptoms of pneumonia in a previously healthy child due to an infection which has been acquired outside hospital. Pneumonia is the leading cause of death in children worldwide. Accurate assessment of severity and prognosis is important to decide management of pneumonia. Objective: The objective of present study is to study role of Chest X-ray in predicting severity of pneumonia in children. Material \& Methods: This was prospective observational type, hospital based study conducted from March 2019 till June 2020 years in Dept. of Radiology \& Imaging Pediatric ward of Dhaka Shishu (Children) Hospital, Dhaka, Bangladesh. A total of 307 children aged 3 months to 59 months diagnosed with Pneumonia \& Severe pneumonia as per World Health Organization (WHO) criteria were included in study. Chest radiographs were reported by Pediatric Radiologist and findings classified as Normal, Primary End point consolidation, Other Infiltrates, Pleural effusion. Results were compared in sub-group i.e. Pneumonia \& Severe Pneumonia. Results: Hypoxia, cyanosis, grunting and severe malnutrition were found to be poor predictors of radiographic pneumonia. Bilateral infiltrates (30\%) \& Primary end point consolidation on right side (17\%) are independent determinant of severity of pneumonia. Bilateral consolidation and bilateral pleural effusion on chest X-ray are associated with poor outcome. Conclusion: Children with cyanosis, grunting, hypoxia \& severe malnutrition should preferentially have chest X-ray done since they are more likely to have consolidation, infiltrates or pleural effusion. Children with Bilateral infiltrates, Consolidation and Bilateral pleural effusion should preferably be admitted to pediatric intensive care unit for more aggressive monitoring and management, since they have poor outcome.

Keywords: Pneumonia, Radiography, Severity, Prognosis, Outcome.

Copyright $\left({ }_{0} 2020\right.$ The Author(s): This is an open-access article distributed under the terms of the Creative Commons Attribution 4.0 International License (CC BY-NC 4.0) which permits unrestricted use, distribution, and reproduction in any medium for non-commercial use provided the original author and source are credited.

\section{INTRODUCTION}

Community acquired pneumonia (CAP) is defined clinically as presence of signs and symptoms of pneumonia in a previously healthy child due to an infection which has been acquired outside hospital [1]. Pneumonia is the leading cause of death globally among children younger than 5 years of age, accounting for an estimated 1.2 million (18\% total) deaths annually [2]. In numerical term, In 2010, 3.6 million (3.3-3.9 million) episodes of severe pneumonia and 0.35 million $(0.31-$ 0.40 million) all cause pneumonia deaths occurred in children younger than 5 years in India [3]. More number of deaths due to pneumonia were reported from Central India [4]. The spectrum of severity of CAP can be mild to severe. The most important decision in the management of CAP is whether to treat the child in the community or refer and admit for hospital-based care.
This decision is best informed by an accurate assessment of severity of illness at presentation and an assessment of likely prognosis. There is no single validated severity scoring system to guide the decision on when to refer for hospital care [1]. In developing countries, childhood pneumonia is diagnosed using clinical parameters, usually based on the cough \& increased respiratory rate [5]. It maximizes the number of children identified \& treated empirically, but it is non-specific \& therefore highly unsuitable for epidemiological purpose [6]. In order to make a definite diagnosis of clinical pneumonia one might need invasive procedure, which make more difficulties in identifying the causative organisms [7]. Hence Plain radiographs remain the most commonly used radiological tool [8]. WHO definition of tachypnea (Respiratory rate $>60 / \mathrm{min}$ for $<2$ months, $>50 /$ min for 2 to 12 months and $>40 /$ min for $>12$ months age) has 
highest sensitivity and specificity for radiographically defined pneumonia [1]. A few studies [9-11], showed that radiological findings are associated with severe CAP in otherwise healthy children and could be considered as marker of disease severity in children with CAP. However, a recent Indian study [12] concluded that radiological findings in hospitalized children with clinically defined severe pneumonia have limited value in predicting clinical outcome. Hence the present study aims to find out role of Chest X-ray in diagnosis \& predicting severity of community acquired pneumonia in children.

\section{Material \& Methods}

This was prospective observational type, hospital based study conducted from March 2019 till June 2020 years in Dept. of Radiology \& Imaging, Pediatric ward of Dhaka Shishu (Children) Hospital, Dhaka, Bangladesh. Sample of 307 children was calculated taking the prevalence of pneumonia in study group to be 275 and error to be $5 \%$. Children aged 3 months to 59 months diagnosed with community acquired pneumonia fulfilling the criteria of WHO defined pneumonia and severe pneumonia [13], was selected by predefined inclusion \& exclusion criteria. Confidentiality of data was ensured.

In all enrolled cases data of basic information, history of exclusive breast feeding [14], immunization status [15], anthropometry [16], overcrowding [17], indoor air pollution (fuels used for cooking, place of cooking, smokers in house), presenting symptoms, physical examination, hypoxia [18] \& hospital stay [19] were entered in predefined case report form. Chest radiographs were performed in Postero-Anterior view \& obtained in standard projections and reporting was done by experienced Pediatric Radiologist, unaware of the clinical findings, following the standardized guidelines for the interpretation of pediatric chest radiograph by WHO [6]. Quality of Chest X-rays was categorized as Un-interpretable, Suboptimal \& Adequate. Radiological findings were classified as Normal, Primary end point consolidation, other infiltrates \& Pleural effusion [6]. These findings were entered in Chest X-ray reporting form. The outcome variables which included cured, death and prolonged hospital stay was documented.

\section{Data Analysis}

The children with pneumonia and severe pneumonia were compared in order to identify any correlations between CAP severity and radiological findings. (Please insert) Categorical variables were given as numbers and percentages and was analyzed using contingency table analysis using Chi-square or Fischer's exact test as appropriate. Association between dependent and independent variables were assessed using multivariate logistic analysis to determine their independent effect on outcome. Diagnostic accuracy of the study variables in detecting significant pathology on chest X-ray was further assessed using sensitivity, specificity and determination of Area under Receiver Operating Curve (ROC). Results were interpreted with OR and 95\% confidence interval. Statistical significance was established when confidence interval (CI) did not embrace unity.

\section{Results}

Out of total 307 children 89 (29\%) cases had pneumonia \& $218(71 \%)$ cases had severe pneumonia. Majority of the study participants i.e. $58 \%$ were infants (3 months to 12 months). Among cases with severe pneumonia, almost two-third of cases i.e $66 \%$ were infant. Overall males $(54.07 \%)$ were more than females $(45.93 \%)$. Two-third $(69 \%)$ of the cases belonged to urban population. Among 307 Chest X-rays, 13 found suboptimal, 146 were normal \& 148 were abnormal. Clinical signs of severity i.e chest in drawing $(\mathrm{p}=0.009)$, cyanosis $(\mathrm{p}=0.001)$, grunting $(\mathrm{p}=0.02)$, convulsions $(\mathrm{p}=0.03)$ and hypoxia $(\mathrm{p}=0.00)$ were associated with abnormal radiographs (Table-1).

Table-1: Association between clinical features $\&$ presence of radiologic pneumonia

\begin{tabular}{|l|l|l|l|l|}
\hline Variables & Radiologic Pneumonia & No Radiologic & Pneumonia Chi-square & p- value \\
\hline Age 3 months- 12 months & $84(57 \%)$ & $88(60 \%)$ & 0.37 & 0.54 \\
\hline Age 13 months-24 months & $35(24 \%)$ & $36(25 \%)$ & 0.04 & 0.83 \\
\hline Age 25 months- 59 months & $29(19 \%)$ & $22(15 \%)$ & 0.74 & 0.38 \\
\hline Fever & $134(91 \%)$ & $126(86 \%)$ & 1.29 & 0.25 \\
\hline Fast breathing & $145(98 \%)$ & $141(96 \%)$ & 0.54 & 0.46 \\
\hline Chest indrawing & $111(75 \%)$ & $89(61 \%)$ & 6.66 & 0.009 \\
\hline Cyanosis & $30(20 \%)$ & $11(8 \%)$ & 9.93 & 0.001 \\
\hline Grunting & $95(64 \%)$ & $75(51 \%)$ & 4.95 & 0.02 \\
\hline Convulsions & $5(3 \%)$ & $00(0 \%)$ & & 0.03 \\
\hline Altered sensorium & $35(24 \%)$ & $31(21 \%)$ & 0.24 & 0.61 \\
\hline Inability to feed & $26(18 \%)$ & $19(13 \%)$ & 1.17 & 0.27 \\
\hline Crackles & $100(67 \%)$ & $98(67 \%)$ & 0.006 & 0.93 \\
\hline Hypoxia & $94(64 \%)$ & $58(40 \%)$ & 16.6 & 0.00 \\
\hline Severe acute malnutrition & $31(20 \%)$ & $13(9 \%)$ & 8.37 & 0.003 \\
\hline Total & 148 & 146 & & \\
\hline
\end{tabular}


On further subjecting the variables to multivariate logistic regression analysis hypoxia, cyanosis, grunting and severe malnutrition were found to be independent predictors of the latter. As shown in Table-2 Hypoxia has a moderate sensitivity (63.5\%) and specificity $(60.2 \%)$ to predict significant pathology on chest X-ray with area under the curve 0.62 (Figure$1)$. Grunting has a moderate sensitivity $(64.1 \%)$ and low specificity (48.6\%) with area under the curve in ROC as 0.56 . Severe malnutrition has a poor sensitivity (20.9\%) and high specificity $(91 \%)$ with area under the curve in ROC as 0.56 whereas Cyanosis has a poor sensitivity $(20.2 \%)$ and high specificity $(92.5 \%)$ to predict significant pathology on chest X-ray with area under the curve in ROC as 0.56 .

Table-2: Diagnostic accuracy of clinical symptoms in predicting significant pathology on chest $x$-ray

\begin{tabular}{|l|l|l|l|l|}
\hline Parameters & $\begin{array}{l}\text { Sensitivity } \\
(\boldsymbol{\%})\end{array}$ & $\begin{array}{l}\text { Specificity } \\
(\boldsymbol{\%})\end{array}$ & $\begin{array}{l}\text { Positive Predictive } \\
\text { Value (\%) }\end{array}$ & $\begin{array}{l}\text { Negative Predictive } \\
\text { Value (\%) }\end{array}$ \\
\hline Hypoxia & 63.5 & 60.2 & 61.8 & 61.9 \\
\hline Cyanosis & 20.2 & 92.5 & 73.1 & 88.2 \\
\hline Grunting & 64.1 & 48.6 & 55.8 & 57.2 \\
\hline Severe acute malnutrition & 20.9 & 91 & 70.4 & 53.2 \\
\hline
\end{tabular}

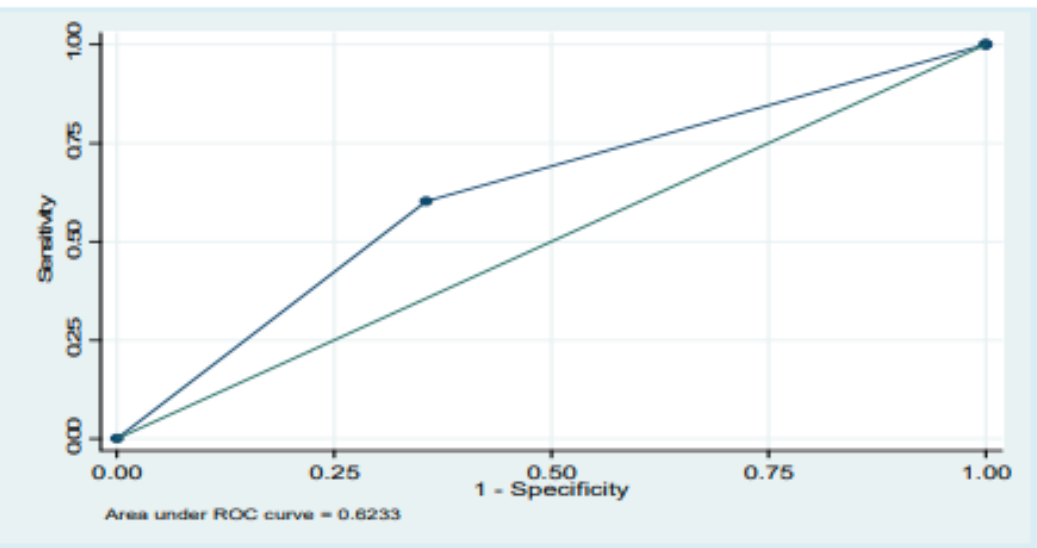

Fig-1: Roc curve for hypoxia in predicting significant pathology on chest $x$-ray

Among abnormal Chest X-rays, severe pneumonia had greatest frequency of Bilateral infiltrates $(n=55,30 \%)$, primary end point consolidation on right side $(\mathrm{n}=32,16 \%)$, bilateral consolidation $(\mathrm{n}=9$, $4 \%)$, bilateral pleural effusion $(\mathrm{N}=6,3 \%)$, left-sided pleural effusion $(\mathrm{N}=3,1.4 \%)$ followed by right sided pleural effusion $(\mathrm{N}=2,1 \%)$. There was a significant association of bilateral infiltrates (OR: 2.03, CI: 1.04-
3.95, $\mathrm{p}=0.04)$ and bilateral consolidation $(\mathrm{p}=0.04$ by fisher exact) as compared to other significant pathology (Table-3). On multivariate analysis primary end point consolidation ( $\mathrm{p}=0.05$, OR: $2.05, \mathrm{CI}: 0.99-4.23)$ and other infiltrates ( $\mathrm{p}=0.012$, OR: 2.27 , CI: $1.19-4.33$ ) were found to be independent determinant of severity of pneumonia

Table-3: Radiological association with severity of pneumonia

\begin{tabular}{|c|c|c|c|c|c|}
\hline Chest X-ray findings & Pneumonia No. (\%) & Severe Pneumonia No. (\%) & Odds ratio & $95 \% \mathrm{CI}$ & $P$ value \\
\hline Normal & $54(66 \%)$ & $92(44 \%)$ & 0.47 & $0.28-0.79$ & 0.004 \\
\hline \multicolumn{6}{|c|}{ Primary end point consolidation } \\
\hline Right & $11(13 \%)$ & $32(16 \%)$ & 1.22 & $0.58-2.55$ & 0.59 \\
\hline Left & $1(1 \%)$ & $1(0.4 \%)$ & 0.41 & $0.02-6.67$ & \\
\hline Bilateral & 0 & $9(4 \%)$ & & & 0.04 \\
\hline \multicolumn{6}{|l|}{ Other infiltrates } \\
\hline Right & $2(3 \%)$ & $6(3 \%)$ & 1.25 & $0.24-6.33$ & 0.78 \\
\hline Left & $1(1 \%)$ & $1(0.4 \%)$ & 0.41 & $0.02-6.67$ & 0.84 \\
\hline Bilateral & $14(16 \%)$ & $55(30 \%)$ & 2.03 & $1.04-3.95$ & 0.04 \\
\hline \multicolumn{6}{|l|}{ Pleural effusion } \\
\hline Right & 0 & $2(1 \%)$ & & & 1 \\
\hline Left & $1(1 \%)$ & $3(1.4 \%)$ & 1.25 & $0.12-12.1$ & 0.84 \\
\hline Bilateral & $3(3 \%)$ & $6(3 \%)$ & 1.25 & $0.24-6.33$ & 0.78 \\
\hline Total & 87 & 207 & & & \\
\hline
\end{tabular}


In the present study association of severe pneumonia was also seen with incomplete immunization $(\mathrm{p}=0.023)$, Non-exclusive breast feeding cases $(p=0.00015)$, severe malnutrition $(p=0.003)$, severe anaemia $(\mathrm{p}=0.008)$, Hypoxia $(\mathrm{p}=0.000)$ and indoor air pollution $(\mathrm{p}=0.001)$. More than half cases with both pneumonia and severe pneumonia were associated with overcrowding however, this association was not statistically significant $(\mathrm{p}=0.910)$. In cases of severe pneumonia, symptoms found were nasal flaring/ chest in drawing (96\%), cyanosis (18\%), grunting $(72 \%)$, convulsions $(2 \%)$, altered sensorium $(30 \%)$, inability to feed or drink in (19\%) and crackles or bronchial breathing on auscultation in (78\%) cases. Overall, there were total 17 deaths $(6 \%)$. All deaths occurred in cases with severe CAP. Mortality had statistically significant association with bilateral consolidation $(\mathrm{p}=0.00)$ and bilateral pleural effusion $(p=0.01)$. Prolonged hospital stay was seen in 220 cases of which $54 \%$ had X-ray with significant pathology with primary end point consolidation (39\%), infiltrates $(52 \%)$ and pleural effusion (9\%). Association of end point consolidation in with prolonged hospital stay was significant $(\mathrm{p}=0.008)$.

\section{DiscUSSION}

In the present study, using WHO (IMCI 2005) classification [13] found $71 \%$ as severe pneumonia and $29 \%$ as pneumonia. Since, the present study was carried out in a tertiary care referral hospital there were more cases of severe pneumonia. More than half of total cases i.e $58 \%$ were infants ( 3 months to 12 months), making it as most common age group for pneumonia in our community which were similar to results found in other studies [11, 20, 21]. More than two-third of the cases $(69 \%)$ belonged to urban population. The urban prediliction in this study may be due to referral bias since this hospital is situated in an urban setup. The radiographic appearance of pneumonia varies with age and with pathogenesis and extent of the disease [23]. In the present study, out of 294 Chest X-rays, 50.6\% had significant pathology and $49.8 \%$ were reported as normal. The 92 normal X-rays in cases with severe pneumonia were subjected to further evaluation and 11 (5\%) were found to have hyperinflation and $13(6 \%)$ had increased Broncho vascular markings. The higher number of normal X-rays may be because infants constituted $58 \%$ of our study population. Also, air trapping and areas of irregular aeration are often the predominant radiographic abnormality of viral pneumonia [23] which can be attributed to the higher percentage of normal X-rays in the present study as bacteremia was seen in more cases with significant pathology on chest X-rays. A few other studies [11, 21, 22] also had higher number of normal $X$-rays in their studies. The present study showed a significant association of bilateral infiltrates (30\%) and bilateral consolidation (4\%) with severe pneumonia. Primary end point consolidation $(14 \%)$ and other infiltrates (19\%) were found to be independent determinant of severe pneumonia on multivariate analysis. A recent western study [24] found multifocal bilateral consolidations were associated with most complicated cases. Maria Patria et al., [9] found multifocal bilateral distribution, the simultaneous involvement of 3 sites \& right hilar consolidation are associated with severe CAP. Though WHO classification does not include hypoxemia as criteria for severity of disease, Present study showed presence of hypoxia in two-third $(68 \%)$ of subjects with severe pneumonia as compared to only $4.04 \%$ with pneumonia which is similar to other studies $[10,11$, 21]. In the present study, children with hypoxia were 2.6 times more likely to have consolidation, infiltration or pleural effusion on chest X-ray $(\mathrm{p}=0.00)$ and was found to be an independent predictor of significant pathology on chest X-ray with moderate sensitivity $(63.5 \%)$ and specificity (60.2\%). Hypoxia was associated with $67 \%$ of cases with radiographic pneumonia in study by Kabra SK et al., [10] and in $61.7 \%$ by Kuti BP et al., [21] Mark Neuman found that subjects with hypoxia are at a higher risk of having radiographic pneumonia [25]. In the present study, the odds of having significant pathology on chest X-ray in patients with cyanosis was 2.8 and it was found to be an independent predictor of significant pathology on chest X-ray with a high specificity $(92.5 \%)$ as also seen in a recent study [21]. In the present study, grunting was found to be an independent predictor of significant pathology on chest X-ray with a moderate sensitivity $(64.1 \%)$ but low specificity $(48.6 \%)$. In the study by Kuti BP et al., [21] the sensitivity and specificity of grunting in identifying radiologic pneumonia was $37.5 \%$ and $77.9 \%$ respectively. In the present study, the area under ROC curve for hypoxia was 0.63 and for cyanosis, grunting and nutrition was 0.56 suggesting that these clinical parameters had a poor predictability for radiographic pneumonia. Very few studies have used ROC to determine diagnostic accuracy for these tests. In study by Kuti BP et al., [21] area under the curve for cyanosis was 0.53 and grunting was 0.57 but they did not find hypoxia and severe acute malnutrition as an independent predictor of radiographic pneumonia on multivariate analysis. In this study, severe pneumonia had a statistically significant association with incomplete immunization $(\mathrm{p}=0.023)$, nonexclusive breastfeeding $(\mathrm{p}=0.00015)$, severe acute malnutrition $(\mathrm{p}=0.011)$, severe anemia $(\mathrm{p}=0.008)$ and indoor air pollution $(\mathrm{p}=0.001)$. But the present study does not show association of overcrowding with severity of pneumonia. In this study, mortality had statistically significant association with bilateral consolidation $(\mathrm{p}=0.00)$ and bilateral pleural effusion $(\mathrm{p}$ $=0.01$ ). Similar association of mortality with bilateral pleural effusion and consolidation is seen in a few recent studies [26].

\section{Conclusion}

Proper history and physical findings are found useful to stratify children at risk for radiographic pneumonia. Children with clinical signs of severity 
including nasal flaring/ chest in drawing, cyanosis, grunting, altered sensorium and hypoxia particularly those with severe acute malnutrition should preferentially have a chest radiograph done because they are more likely to have evidence of consolidation, infiltrates or pleural effusion. Children with bilateral consolidation, bilateral infiltrates and bilateral pleural effusion should preferably be admitted to pediatric intensive care unit for more aggressive monitoring and management that could reduce their mortality, since they have a poor outcome.

\section{REFERENCES}

1. Harris M, Clark J, Coote N, Fletcher P, Harnden A, McKean M, Thomson A; British Thoracic Society Standards of Care Committee. British Thoracic Society guidelines for the management of community acquired pneumonia in children: update 2011. Thorax. 2011 Oct; 66 Suppl 2:ii1-23. doi: 10.1136/ thoraxjnl-2011-200598.

2. Nelson Textbook of Pediatrics .20th ed. Kleigman, Staton, St Geme and Schor, 2015:2088-2089

3. Farooqui H, Jit M, Heymann DL, Zodpey S. Burden of Severe Pneumonia, Pneumococcal Pneumonia and Pneumonia Deaths in Indian States: Modelling Based Estimates. PLoS One. 2015 Jun 18; 10 (6):e0129191. doi: 10.1371/journal.pone.0129191. eCollection 2015.

4. Causes of neonatal and child mortality in India: A nationally representative mortality survey-Causesof-neonatal-and-child- mortality-in-India2010.pdf. Available from: http://cghr. Org/wordpress /wp -content/ uploads/ Causes -ofneonatal-and-child-mortality-in-India- 2010.

5. Revised WHO classification and treatment of childhood pneumonia at health facilities. Geneva, World Health organization, 2014:19-20.

6. Cherian T, Mulholland EK, Carlin JB, Ostensen H, Amin R, de Campo M, Greenberg D, Lagos R, Lucero M, Madhi SA, O'Brien KL, Obaro S, Steinhoff MC. Standardized interpretation of paediatric chest radiographs for the diagnosis of pneumonia in epidemiological studies. Bull World Health Organ. 2005 May; 83(5):353-9. Epub 2005 Jun 24.

7. Campos JM. Haemophilus. In: Murday PR (editor) Manual of clinical microbiology. (7th edn) Washington. PC: 1998; 604.

8. Sheikh Q, Zulfiqar B. Role of chest X-ray in diagnosis of lower respiratory tract infections in children less than 5 years of age in community. Pak. J Med Sc: October-December 2005; 21(4):417-421.

9. Patria MF, Longhi B. Association between radiological findings and severity of communityacquired pneumonia in children. Italian Journal of Pediatrics. 2013; 39:56. doi: 10.1186/1824-728839-56.

10. Tiewsoh K, Lodha R, Pandey RM, Broor S, Kalaivani M, Kabra SK. Factors determining the outcome of children hospitalized with severe pneumonia. BMC Pediatr. 2009 Feb 23; 9:15.doi: 10. 1186 / 1471-2431-9-15.

11. Basnet S, Sharma A, Mathisen M, Shrestha PS, Ghimire RK Shrestha DM, Valentiner-Branth P, Sommerfelt H, Strand TA. Predictors of duration and treatment failure of severe pneumonia in hospitalized young Nepalese children. PLoS One. 2015 Mar 23; 10 (3): e0122052. doi: 10.1371/journal.pone.0122052. E Collection 2015.

12. Bharti B, Kaur L, Bharti S. Role of chest X-ray in predicting outcome of acute severe pneumonia. Indian Pediatr. 2008 Nov; 45(11):893-8.

13. Handbook IMCI. Integrated Management of Childhood Illness. By World Health Organization (WHO). 2005.

14. Patel A, Bang A, Singh M. A Randomized Controlled Trial of Home based Oral Amoxicillin for severe Pneumonia in children aged 3-59 months: The India CLEN Severe Pneumonia Oral Therapy Study. BMC Pediatrics. 2015, Nov. 15:186 : DOI: $10.1186 /$ s12887 -015-0510-9

15. Jackson S, Mathews KH, Pulanić D, Falconer R, Rudan I, Campbell H, Nair H. Risk factors for severe acute lower respiratory infections in children-a systematic review and meta-analysis. Croatian medical journal. 2013 Apr 15; 54(2):11021.

16. Use and interpretation of anthropometric indicators of nutritional status. WHO Working Group. Bull World Health Organ. 1986; 64(6):929-41

17. Park K. Park's Textbook of Preventive and Social Medicine. 23rd ed. 2015

18. Basnet S, Adhikari RK, Gurung CK. Hypoxemia in children with pneumonia and its clinical predictors. The Indian journal of pediatrics. 2006 Sep 1;73(9):777-81.

19. Principi N, Esposito S: Management of severe community-acquired pneumonia of children in developing and developed countries. Thorax. 2011, 66: 815-822. Doi 10.1136/thx2010.142604.

20. Mathisen M, Strand TA, Sharma BN, Chandyo RK, Valentiner-Branth P, Basnet S, Adhikari RK, Hvidsten D, Shrestha PS, Sommerfelt H. Clinical presentation and severity of viral community acquired pneumonia in young Nepalese children. Pediatr Infect Dis J. 2010 Jan; 29(1):e1-6. doi: 10.1097/INF.0b013e3181c2a1b9.

21. Kuti BP, Adegoke SA, Oyelami OA. Can we predict which children with clinical pneumonia will have radiologic findings on chest radiograph. World J Med Med Sci. 2014 Mar;2(3):1-12.

22. Ali Salih KEM, Wahb OA, Ibrahim SA. Radiological Findings in Severe Pneumonia in Children 1-59 Months in a Children's Hospital, Khartoum, Sudan. Pediatr Therapeut. 2012; 2:117. doi:10.4172/ 2161-0665.1000117

23. Jerald PK, Thomas S, Jack OH. Caffey's Pediatric Diagnostic Imaging. 10th ed, 1: 987-995. 
24. Bay A, Etlik O, Oner AF, Unal O, Arslan H, Bora A, Davran R, Yuca SA, Dogan M. Radiological and clinical course of pneumonia in patients with avian influenza H5N1. Eur J Radiol. 2007 Feb; 61(2):245-50. Epub 2006 Nov 15.

25. Neuman MI, Monuteaux MC, Scully KJ, Bachur RG. Prediction of pneumonia in a pediatric emergency department. Pediatrics. 2011 Aug 1;128(2):246-53.
26. Iroezindu MO, Chima EI, Isiguzo GC, Mbata GC, Onyedum CC, Okoli LE. Determinants Of InHospital Mortality From Community Acquired Pneumonia In Nigerian Adults: A Five Year Multi-Centre Case-Control Study. InD108. Pneumonia Epidemiology And Outcomes, 2014 May (pp. A6514-A6514). American Thoracic Society. 